\title{
Exchange transfusion in complicated pediatric malaria: A critical appraisal
}

\author{
Himesh Barman
}
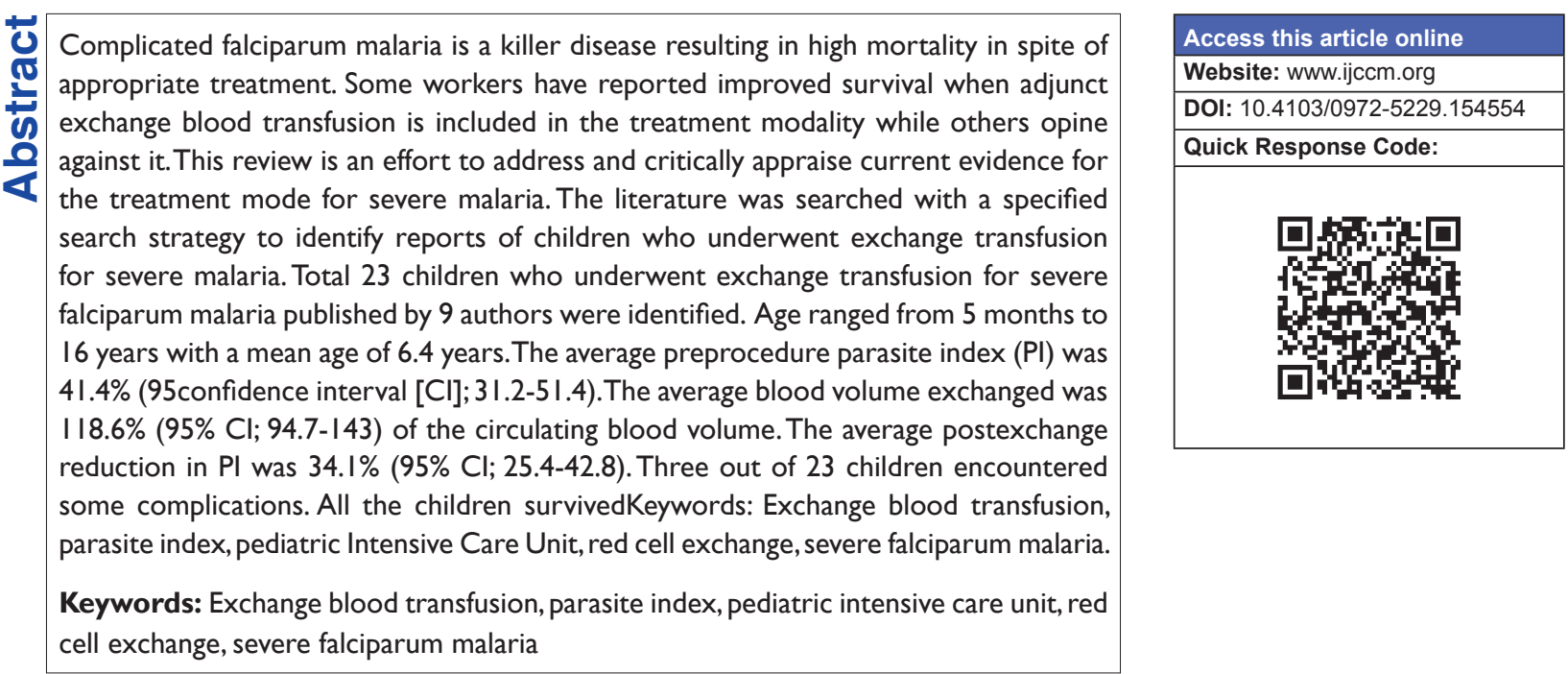

\section{Introduction}

Malaria is a protozoan disease caused by five species of Plasmodium. Out of which Plasmodium falciparum is the major killer as it causes the most serious disease. Antimalarials are the mainstay of treatment, which may sometime fail due to overwhelming parasitic load and/or lack of enough time for the drug to act before the disease kills. Exchange blood transfusion (EBT) was first performed in 1974. Since then there have been several anecdotal reports and case series claiming benefit for EBT in severe malaria though no comparative trials exits. Till now there is no consensus as to how it might work or whether it reduces mortality or not. ${ }^{[1]}$ The current status, technique, benefits and controversies surrounding EBT are reviewed in this article. Keeping

From:

Department of Pediatrics, North Eastern Indira Gandhi Regional Institute of Health and Medical Sciences, Shillong, Meghalaya, India

Correspondence:

Dr. Himesh Barman, Department of Pediatrics, North Eastern Indira Gandhi Regional Institute of Health and Medical Sciences, Shillong, Meghalaya, India.

E-mail: himeshbarman@gmail.com in mind the abundance of malaria and resource limited nature of these areas; both doing and not doing the procedure may have huge implication in terms of lives saved, blood units consumed and optimum manpower utilization.

\section{Applied microbiology}

Malarial infection in the human being stated with inoculation of plasmodial parasite by female anopheles mosquito. The parasite pass through the developmental phase in the parenchymal cells of the liver then enter the red blood cells (RBCs) where they undergo erythrocytic schizogony leading to rupture of RBCs releasing 8-32 merozoites. These merozoites invade other RBCs and continue the cycle. Plasmodium vivax and Plasmodium ovale infects young RBCs (reticulocytes), Plasmodium malariae infects old RBCs, and P. falciparum infects both young and old RBCs. Hence, counts of parasitized RBCs are around $25,000 / \mu 1$ with $P$. vivax, $P$. ovale, $P$. malariae but may exceed 500,000 with P. falciparum. ${ }^{[2,3]}$ After parasite invasion, RBCs are progressively modified. New structures appear inside the RBCs, and novel 
parasitic proteins are exported to cell the membrane. Radical biochemical, morphological and rheological alteration results in increased $\mathrm{RBC}$ membrane rigidity and reduced $\mathrm{RBC}$ plasticity and the greater adhesiveness of the cell membrane, which leads micro vascular slugging and capillary clogging. ${ }^{[4-8]}$ Activation of the inflammatory system with production of cytokines leads to complication of severe falciparum malaria. ${ }^{[9-11]}$

\section{Hyperparasitemia as a marker of disease severity}

A high parasite load accelerates pathological process, which increases the likelihood of developing severe malaria leading to higher treatment failure rates. Of particular concern is resistance to antimalarials, which is most likely to arise in patients with heavy parasite burdens. ${ }^{[1,12]}$ In the absence of any direct way to measure the parasite load and peripheral parasitemia has been used as a surrogate marker. Patients with high parasite index (PI) are known to be at increased risk of dying, although the relationship between parasite counts and prognosis varies at different levels of malaria endemicity. World Health Organization (WHO) define hyperparasitemia as $>5 \%$ in low transmission setting and $>10 \%$ in high transmission setting. ${ }^{[1]}$ In $P$., falciparum infection parasitized erythrocytes may be sequestrated inside the tissue capillaries resulting in a falsely low PI. ${ }^{[4,7,8]}$ In such instances the development stages of the parasite seen on painful bladder syndrome help to access the severity better than PI alone. The presence of more mature parasite forms ( $>20 \%$ of parasites as late trophozoites and schizonts) and of more than 5\% of neutrophils containing malarial pigment indicates advanced disease and worse prognosis. ${ }^{[4,7]}$

\section{Rationale for exchange blood transfusion}

Hyperparasitemia is associated with increased mortality. Rapidly bringing down parasitic index is expected to cause survival benefit. Several case repots and series have concluded that EBT used in adjunct to chemotherapy can rapidly reduce parasitic index more rapidly compared to chemotherapy alone resulting in survival benefit. ${ }^{[13-23]}$ The postulated mechanisms by which EBT is proposed to work effectively as adjunct therapy are following: $[1,7,10,11]$

- Decreases the parasitic burden quickly

- Improves red cell deformability and microvascular clogging

- Decreases risk of intravascular hemolysis

- Increases hematocrit and thereby improves oxygen-carrying capacity of blood

- Removes toxic substances like tumor necrosis factor alpha and other pro-inflammatory cytokines.

\section{Methodology}

Defined search strategies were employed to search MEDLINE using limit of age $0-18$ years.

- Strategy 1: ("Exchange Transfusion, Whole Blood" [Mesh]) AND ("Malaria, Falciparum" [Mesh] OR "Malaria, Cerebral” [Mesh] OR “Malaria" [Mesh] OR "Blackwater Fever" [Mesh]) - yielded 36 papers. Ongoing through the abstracts, only 6 articles found to report on exchange transfusion in malaria in children $^{[22-27]}$

- Strategy 2: Erythrocytapheresis AND malaria yielded 3 relevant results. ${ }^{[28-30]}$

Informal search of the literature yielded another relevant publication. ${ }^{[31]}$ However, there is the apparent duplication of the cases of reference 30 in reference 31. Hence, these cases of reference 30 were excluded from the analysis.

\section{Results of the literature search}

A 4 case series and 5 case reports of EBT in severe malaria in children were found. This included 23 children - 15 children undergoing manual exchange and 8 therapeutic red cell exchange (TREX) and tabulated in Table 1. The mean age was 6.4 years with a range of 5 months to 16 years. No controlled trial of exchange transfusion in severe malaria in children was found.

\section{Indications and technique}

All except one, exchange transfusions were done in children presenting with hyperparasitemia $>5 \%$. The average preprocedure hyperparasitemia was $41.4 \%$ (95\% confidence interval [CI];31.2-51.4) and all of them had one or more complications of severe malaria apart from hyperparasitemia. Only one case underwent exchange transfusion for severe malaria without hyperparasitemia. ${ }^{[25]}$ In most cases, exchange transfusion was resorted to once there was no improvement on conventional therapy alone. Some authors did it within hours of admission in cases with severe malaria and hyperparasitemia. The manual procedures were done via central venous catheters by push-pull technique or pull from the radial artery and push by a peripheral vein. Erythrocytapheresis were done via central catheters. TREX tended to take less lime compared with the manual exchange.

\section{Blood volume used}

Different authors used different blood volumes for exchange transfusion ranging from partial exchange 


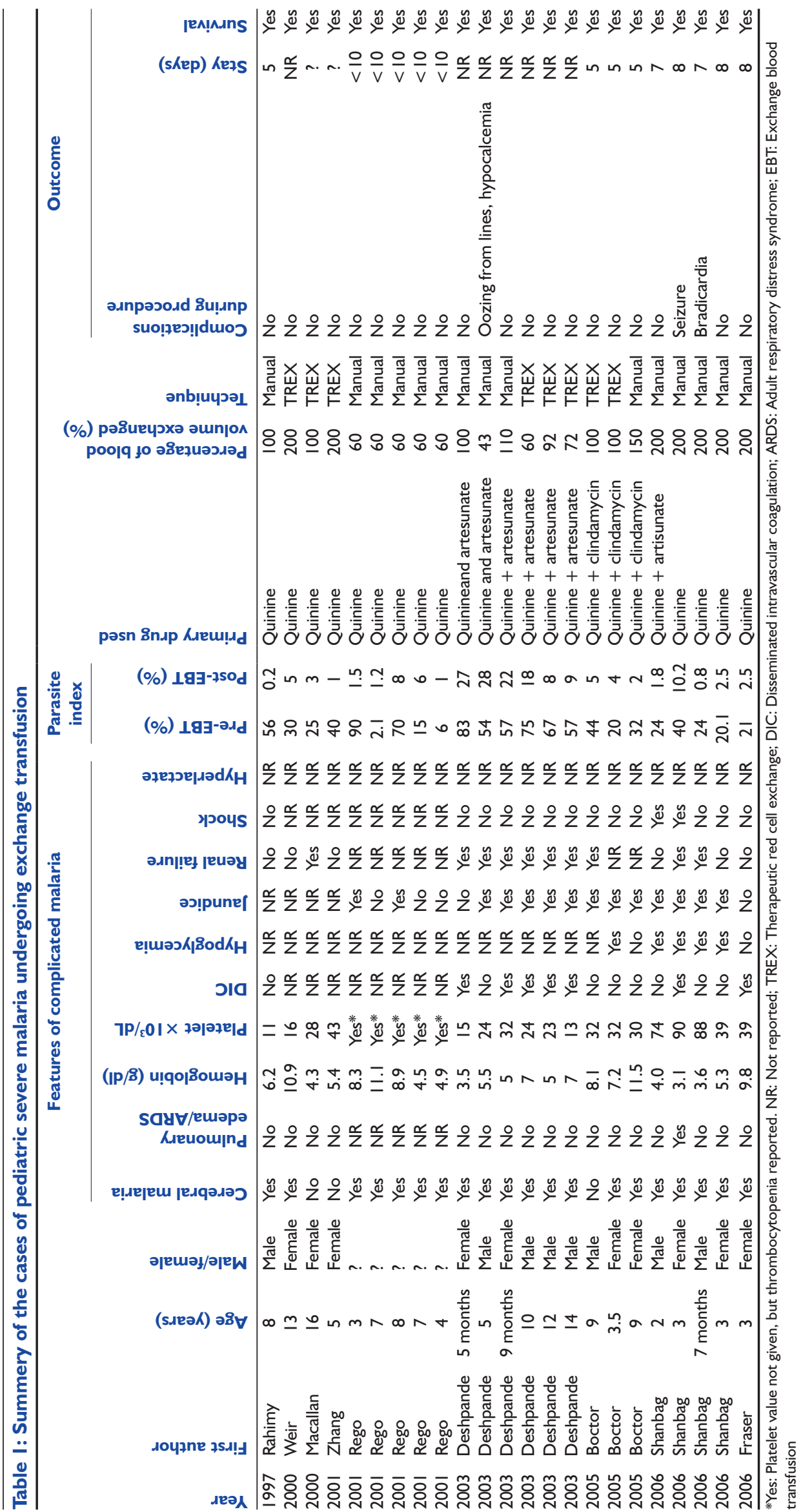


transfusion $(40 \mathrm{ml} / \mathrm{kg})$ to double volume exchange transfusion $(160 \mathrm{ml} / \mathrm{kg})$. In this article, the proportion of blood volume exchanged is expressed in percentage of total circulating blood volume. The average volume used was $118.6 \%$ (95\% CI; 94.7-143) of the circulating blood volume of the child. Mean blood volume used in TREX and manual exchange was not significantly different (mean: 115.5 [95\% CI; 78.0-153.0] vs. mean: 120 [95\% CI; 87.5-152.5], $P=0.84$ ).

\section{Efficacy}

On an average around $4 / 5^{\text {th }}$ of preexchange PI was reduced by exchange transfusion (mean $81.2 \%$ [95\% CI; 74.7-84.5]) and it happened irrespective of the preexchange PI $\left(r^{2}=0.01\right)$. Therefore, as would be expected, the absolute reduction in PI (preexchange PI - postexchange PI) was more when preexchange PI was high $\left(r^{2}=0.89\right)$ [Figure 1]. The average absolute postexchange reduction in PI was $34.1 \%$ (95\% CI; 25.4-42.8). The decrease in PI in manual exchange (mean 31.9 [95\% CI 19.7-44.1]) and TREX treated children (mean 38.12 [95\% CI; 27.0-49]) were not statically different $(P=0.46)$. There was no correlation between the percentage of blood volume exchanged and reduction in PI $\left(r=-0.26, r^{2}=0.07\right)$. Whether quinine or artisunate was used did not determine the relative drop of PI $(P=0.2)$. All the children survived intact without and sequelae and required around 5-10 days to get a discharge.

\section{Safety}

Some adverse events such as seizure during procedure, hypocalcemia, oozing from lines and bradicardia were reported in 3 out of 23 children. All the reported adverse events were in manual exchange group.

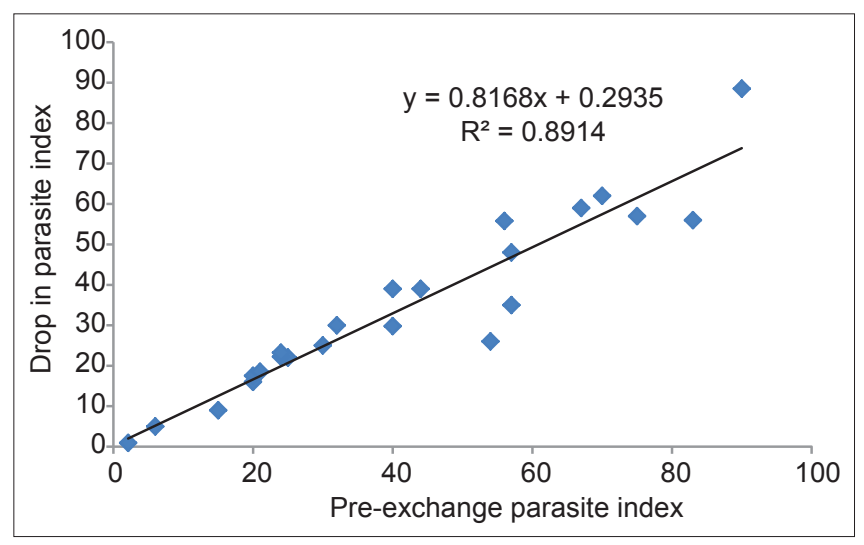

Figure I: Scatter diagram showing the relation of preexchange parasite index $(\mathrm{PI})(\mathrm{X}$-axis) and the absolute drop in $\mathrm{PI}$ postexchange transfusion (Y-axis)

\section{Discussion}

Though exchange transfusion has come with big expectation but it is still far from being uniformly accepted. The indications of EBT and amount of blood to be exchanged are still hazy. Though there are in literature regarding its efficacy and safety in adults, the evidence base in children is very small. Main outcome variables highlighted in most reports are rapidity of parasite clearance and survival. A striking drop of PI has been demonstrated irrespective of the technique used or percentage of blood volume exchanged. All reported children survived. However, absence of a control arm in any of the reports makes the interpretation difficult. Postexchange rise in hematocrit as an outcome variable could not be determined by this review due to lack of data. Apparently, TREX took lesser time and is better tolerated but at added cost. On other hand, quite a number of reports also exist in the literature questioning the place of exchange transfusion in complicated malaria with hyperparasitemia.

Various case series and case reports in adults have documented a significantly more rapid decline in peripheral parasitemia with use of adjunct exchange transfusion when compared to antimalarials alone. The procedure had an added benefit of elevating the hemoglobin without causing volume overload. All of the studies in this review show a positive outcome and a $100 \%$ survival points toward the possibility of publication bias. No reports comparing exchange transfusion in children with chemotherapy alone was found. Therefore, exchange transfusion in severe malaria with hyperparasitemia in children is far from being a "magic bullet". Mordmüller and Kremsner demonstrated successful treatment of complicated malaria in children with hyperparasitemia up to as high as $81 \%$ with chemotherapy alone and questioned the need for exchange transfusion for hyperparasitemia. ${ }^{[32]} \mathrm{A}$ large retrospective series in adults by Burchard et al. found that exchange transfusion did not significantly improve the unfavorable prognosis in cases of severe falciparum malaria. ${ }^{[33]}$ A meta-analysis by Riddle et al. including 8 studies in adult derived a similar conclusion. ${ }^{[34]}$ They found that the use of exchange transfusion was not associated with an increased survival rate, however, patients treated with exchange transfusion had higher levels of parasitemia, and higher number of WHO criteria met. When adjusted for malaria-immunity status, the initial level of parasitemia, and number of WHO criteria met, the use of exchange transfusion was still not associated with an increased survival rate. When stratified by degree of parasitemia or by number of WHO criteria met, there 
was no evidence of an improved survival rate among patients treated with exchange transfusion who had any level of parasitemia or met any number of WHO criteria for severe or complicated malaria. This analysis looked only at survival as the outcome. However, other important outcomes to measure the success of adjunct exchange transfusion such as length of coma, duration of stay in an intensive care unit, duration of fever in the hospital, and onset or presence of residual complications needs to be investigated.

Currently, centers for disease control recommends that exchange transfusion be performed in $P$. falciparum infection when parsitemia is $\geq 10 \%$. In patients with coma, renal failure, or adult respiratory distress syndrome, EBT is recommended regardless of the level of parasitemia even if $<10 \% .{ }^{[9]}$ However, in absence of consensus on the indications, benefits and dangers involved, or on practical details such as the volume of blood that should be exchanged, WHO expressed inability to make any recommendation regarding its use. ${ }^{[1]}$ As most studies of EBT are carried out in quinine treated patient, its relevance in the context of rapid malaricidal ability of artemisinin compound is a different arena. A recent study in adults has demonstrated no benefit of adjunct exchange transfusion in artemisinin treated patients. ${ }^{[35]}$ In our current literature search, the drug used did not impact the reduction in hyperparasitemia. However, only 7 children treated with exchange transfusion were treated with artisunate, and the number is too small to draw a valid conclusion.

\section{Points to ponder in exchange transfusion for malaria}

- No controlled trial in children is available to prove the efficacy of exchange transfusion in complicated malaria with hyperparasitemia. Even in adults, there is no well-designed randomized controlled trial with sufficient power till date. The efficacy is highlighted by case series and case reports only. Publication bias is a real possibility as workers with negative study results are less likely to publish their results

- Peripheral blood parasitemia may not be the surrogate marker for disease severity as there is no correlation between peripheral parasitemia and sequestrated parasitized RBCs. Most harmful proportion of parasitized RBCs is not exchanged as they are locked in capillaries

- The main idea about exchange transfusion is peripheral parasitemia rapidly which is also achieved by artisunate therapy. Hence, it makes a strong case against exchange transfusion. Most comparative studies are undertaken in-patient receiving quinine as chemotherapy

- If exchange transfusion fails to show more efficacy compared to artemisinin compound, packed red blood cell (PRBC) transfusion may cause more rise of hematocrit and thereby better red cell deformability and oxygen-carrying capacity per unit blood used compared to exchange transfusion. This may have a huge implication in resource limited areas

- The potential benefit of elimination of inflammatory mediators and toxins are probably not important because TREX, where unlike manual exchange, the plasma is returned back to the patient, has also been proved to be equally effective.

\section{Conclusions}

Exchange transfusion is far from being practical and proven mode of therapy in the malaria endemic developing nations areas where it is needed most. Though a sizable number of case report and a series or nonrandomized trial showed benefit in adults, the evidence base in children is very small, and it may have to be interpreted with caution. A well-designed randomized controlled trial with sufficient sample size is a necessity as publication bias is a real possibility. This labor-intensive method may be reserved as a salvage therapy only and not a routine for all complicated malaria with hyperparasitemia in areas where blood and intensive care facilities are not plentiful. In such areas, judicious use of blood to treat anemia by PRBC transfusion may be able to save more lives than using several unit for every single exchange. Partial exchange transfusions if proved to be beneficial will be boon to such areas. It may also be interesting to see whether, in the absence of TREX, manual partial exchange transfusion with PRBC instead of whole blood will me more effective in elevating hematocrit without losing efficacy of lowering parasitemia.

\section{References}

1. World Health Organization. Treatment of severe falciparum malaria. In: Guideline for Treatment of Malaria. Geneva: World Health Organization; 2006. p. 41-61.

2. McKenzie FE, Jeffery GM, Collins WE. Plasmodium malariae blood-stage dynamics. J Parasitol 2001;87:626-37.

3. McKenzie FE, Jeffery GM, Collins WE. Plasmodium vivax blood-stage dynamics. J Parasitol 2002;88:521-35.

4. Gilles HM. The malaria parasites. In: Gilles HM, Warrell DA, editors. Bruce-Chwatt's Essential Malariology. London, Boston, Melbourne, Auckland: Edward Arnold; 1993. p. 12-34.

5. Krogstad DJ. In: Mandell GL, Bennett JE, Dolin R, editors. Principles and Practice of Infectious Diseases. New York: Churchill Livingstone; 1995. p. 2415-27. 
6. McQueen PG, McKenzie FE. Age-structured red blood cell susceptibility and the dynamics of malaria infections. Proc Natl Acad Sci U S A 2004;101:9161-6.

7. Newton CR, Krishna S. Severe falciparum malaria in children: Current understanding of pathophysiology and supportive treatment. Pharmacol Ther 1998;79:1-53.

8. Cooke BM, Mohandas N, Coppel RL. Malaria and the red blood cell membrane. Semin Hematol 2004;41:173-88.

9. Clark IA, Budd AC, Alleva LM, Cowden WB. Human malarial disease: A consequence of inflammatory cytokine release. Malar J 2006;5:85.

10. Maegraith B. Other pathological processes in malaria. Bull World Health Organ 1974;50:187-93.

11. Trampuz A, Jereb M, Muzlovic I, Prabhu RM. Clinical review: Severe malaria. Crit Care 2003; 7:315-23.

12. White NJ, Pongtavornpinyo W, Maude RJ, Saralamba S, Aguas R, Stepniewska K, et al. Hyperparasitaemia and low dosing are an important source of anti-malarial drug resistance. Malar J 2009;8:253.

13. Powell VI, Grima K. Exchange transfusion for malaria and Babesia infection. Transfus Med Rev 2002;16:239-50.

14. Beards SC, Joynt GM, Lipman J. Haemodynamic and oxygen transport response during exchange transfusion for severe falciparum malaria. Postgrad Med J 1994;70:801-4.

15. Kumar S, Karnad DR, Vaingankar J, Thatte UM, Krishnan A, Rege NN. Serum tumour necrosis factor alpha levels in severe malaria: Effect of partial exchange transfusion. Intensive Care Med 2003;29:1857-8.

16. Hall A, Yardumian A, Marsh A. Exchange transfusion and quinine concentrations in falciparum malaria. Br Med J (Clin Res Ed) 1985;291:1169-70.

17. Pinanong M. Exchange transfusion therapy in severe complicated malaria. J Med Assoc Thai 1997;80:332-7.

18. Srichaikul T, Leelasiri A, Polvicha P, Mongkonsritragoon W, Prayoonwiwat W, Leelarsupasri S, et al. Exchange transfusion therapy in severe complicated malaria. Southeast Asian J Trop Med Public Health 1993;24 Suppl 1:100-5.

19. Hoontrakoon S, Suputtamongkol Y. Exchange transfusion as an adjunct to the treatment of severe falciparum malaria. Trop Med Int Health 1998;3:156-61.

20. Looareesuwan S, Phillips RE, Karbwang J, White NJ, Flegg PJ, Warrell DA. Plasmodium falciparum hyperparasitaemia: Use of exchange transfusion in seven patients and a review of the literature. Q J Med 1990;75:471-81.

21. Gulprasutdilog S, Chongkolwatana V, Buranakitjaroen P, Jaroonvesama N. Exchange transfusion in severe falciparum malaria. J Med Assoc Thai 1999;82:1-8.

22. Boctor FN. Red blood cell exchange transfusion as an adjunct 296 treatment for severe pediatric falciparum malaria, using automated 297 or manual procedures. Pediatrics 2005;116:592-5.

23. Shanbag P, Juvekar M, More V, Vaidya M. Exchange transfusion in children with severe falciparum malaria and heavy parasitaemia. Ann Trop Paediatr 2006;26:199-204.

24. Fraser IP, Cserti CM, Dzik WH. Case records of the Massachusetts General Hospital. Case 32-2006. A 3-year-old girl with fever after a visit to Africa. N Engl J Med 2006;355:1715-22.

25. Rego SJ, Subba Rao SD, Hejmadi A, Rekha S. Partial exchange transfusion as an adjunct to the treatment of severe falciparum malaria in children. J Trop Pediatr 2001;47:118-9.

26. Weir EG, King KE, Ness PM, Eshleman SH. Automated RBC exchange transfusion: Treatment for cerebral malaria. Transfusion 2000;40:702-7.

27. Boctor FN, Ali NM, Choi YJ, Morse EE. Exchange transfusion with red blood cells preserved in adenine clears a child of severe falciparum malaria. Ann Clin Lab Sci 1997;27:193-5.

28. Deshpande A, Kalgutkar S, Udani S. Red cell exchange using cell separator (therapeutic erythrocytapheresis) in two children with acute severe malaria. J Assoc Physicians India 2003;51:925-6.

29. Zhang Y, Telleria L, Vinetz JM, Yawn D, Rossmann S, Indrikovs AJ. Erythrocytapheresis for Plasmodium falciparum infection complicated by cerebral malaria and hyperparasitemia. J Clin Apher 2001;16:15-8.

30. Macallan DC, Pocock M, Robinson GT, Parker-Williams J, Bevan DH. Red cell exchange, erythrocytapheresis, in the treatment of malaria with high parasitaemia in returning travellers. Trans $\mathrm{R}$ Soc Trop Med Hyg 2000;94:353-6.

31. Udani S, Deshpande A, Kalgutkar S. Exchange transfusion for severe malaria: A comparisison of red cell exchange with whole blood exchange. Indian J Crit Care Med 2003;7:124-7.

32. Mordmüller B, Kremsner PG. Hyperparasitemia and blood exchange transfusion for treatment of children with falciparum malaria. Clin Infect Dis 1998;26:850-2.

33. Burchard GD, Kröger J, Knobloch J, Hartmann WJ, Eichenlaub D, Moling O, et al. Exchange blood transfusion in severe falciparum malaria: Retrospective evaluation of 61 patients treated with, compared to 63 patients treated without, exchange transfusion. Trop Med Int Health 1997;2:733-40.

34. Riddle MS, Jackson JL, Sanders JW, Blazes DL. Exchange transfusion as an adjunct therapy in severe Plasmodium falciparum malaria: A meta-analysis. Clin Infect Dis 2002;34:1192-8.

35. Kreeftmeijer-Vegter AR, Melo Mde M, de Vries PJ, Koelewijn R, van Hellemond JJ, van Genderen PJ. Manual blood exchange transfusion does not significantly contribute to parasite clearance in artesunate-treated individuals with imported severe Plasmodium falciparum malaria. Malar J 2013;12:115.

How to cite this article: Barman $\mathrm{H}$. Exchange transfusion in complicated pediatric malaria: A critical appraisal. Indian J Crit Care Med 2015;19:214-9.

Source of Support: Nil, Conflict of Interest: None declared. 